\title{
Cultura e organizações públicas
}

\author{
Moema Miranda de Siqueira
}

\section{Origem do tema cultura nos estudos organizacionais}

A evolução do conceito de cultura organizacional se deu a partir da constatação das limitações dos instrumentos c métodos utilizados tradicionalmente no estudo das organizações para análises mais complexas. A restrita capacidade de entendimento e interpretação dos fenômenos organizacionais apenas com base $\mathrm{cm}$ seus aspectos mais evidentes, especialmente os de estrutura, exigia novas abordagens. A Teoria Contingencial dos anos 80 , que colocava as organizações como dependentes do ambiente (LAURENCE \& LORSCH, 1973) e condicionando seu succsso ao desenvolvimento de estratégias e estruturas adequadas a este, pode ser considerada como um antecedente do enfoque cultural. $\mathrm{Na}$ medida $\mathrm{cm}$ que os estudos contingencialistas foram constatando a complexidade do ambiente, introduziram novas variáveis para seu entendimento, como a tecnologia e a cultura, entendida esta última, grosso modo, como o conjunto dos valores sociais prevalentes. Posteriormente, a preocupação cstendcu-sc à cultura interna das organizações que, embora condicionada por variáveis do ambiente externo, possuiria caráter próprio. A partir dai, proliferaram os estudos sobre o tema, sendo que, cm 1983, a Administrative Science Quartely publicou um número especial sobre cultura das organizações.

$\mathrm{Na}$ consolidação do tema, foram decisivos os estudos sobre conflitos c suas formas de regulamentação, cujas análises obrigam a se ultrapassar os aspectos puramente técnicos e administrativos do problema. Por outro lado, o conhecimento da cultura de uma organização passou a ser considerado essencial para viabilizar as estratégias e os processos de mudança.

Mocma Miranda de Siqueira é Professora 'Titular aposentada da UFMG, Doutora em Administração - USP, Pesquisadora do CNPq 


\section{Principais enfoques}

Com a proliferação dos estudos sobre cultura nos últimos anos, cresceu a preocupação em se criar tipologias que os identificassem com as diferentes abordagens. SMIRCiCH (1983), por exemplo, separa aqueles que tratam a cultura como alguma coisa que a organização tem, $\mathrm{cm}$ contraste com aqueles que a consideram como algo que a organização é.

A classificação que se segue não tem a pretensão dc criar uma tipologia referencial para os estudos de cultura organizacional e muito menos incorpora uma revisão de literatura completa e atualizada. Tem muito mais o objetivo didático de organizar alguns estudos significativos sobre o tema, ressaltando aspectos de maior proximidade teórica c metodológica, buscando facilitar as opções para os interessados $\mathrm{cm}$ pesquisar um tema tão complexo. Na verdade, as áreas de interseção dos trabalhos são maiores do que as divergentes, obrigando a um csforço e artificio para a identificação de um enfoque nesta ou naquela abordagem.

\subsection{Abordagem comportamental}

\subsubsection{Enfoque sistêmico}

A partir do comportamento das pessoas, passível de observação e mensuração, os estudos nesta linha sistematizam caracteristicas consideradas básicas de um grupo ou organização e, então, identificam individuos desajustados, sugerindo medidas adaptativas nas relações humanas. A cultura, assim, seria gerenciável e fundamental para o desenvolvimento de processos de mudança. Nesta visão, identificada como corporate culture, esta é considerada como um subsistema da organização e possui um aspecto prático, como fonte de referências e de coerência da personalidade da organização. Chegam a ser indicados momentos mais propicios para as mudanças culturais, como as crises por fatores exógenos ou endógenos, sendo a sucessão um exemplo.

Complementando esta visão, autores como Handy (1978) procuram salientar a diversidade dos valores, normas e crenças refletidas nos diferentes comportamentos dentro das organizações, o que significa reconhecer que as organizações possuem várias culturas, ou seja, subsistemas do conjunto de valores e crenças. Os diferentes status e respectivos papéis no interior das organizações têm sido relacionados a diferentes modos de pensar c agir.

Em cstudo de 1992, SalazAR propõe quatro subsistemas da cultura organizacional: a cultura do poder, dependente do centro de decisões; a 
cultura de papéis, baseada nas funções ou especialidades e suas exigências e qualificações; a cultura da tarefa, resultante do trabalho nos grupos; e a cultura da pessoa, centrada no individuo e seu contrato psicológico com a organização.

\subsubsection{Enfoque de clima organizacional}

A partir de modelos de mensuração, este enfoque procura avaliar o grau de satisfação/insatisfação dos empregados em relação a determinadas características organizacionais, especificamente às propriedades motivacionais do ambiente organizacional. Por clima organizacional entende-se o conjunto das percepções que os individuos têm a respeito da organização em que trabalham e que influenciam o seu comportamento e desempenho. Esta avaliação reflete o processamento de informações provenientes de características da própria organização (variáveis estruturais), características inerentes ao próprio indivíduo (variáveis de perfil) e fatos objetivos e vivenciados pelos integrantes da organização (variáveis de contexto). Desta forma, a tarefa de se definir o clima de uma organização é desafiadora, pois, alćm da própria realidade que se tenta apreender ser complexa e multifacetada, a percepção de cada individuo ou grupo de individuos sobre ela também o é. Existem vários constructos para avaliação de clima nas organizações, sendo alguns deles de origem estrangeira, já adaptados ao Brasil. Nas escalas de ambiente de trabalho são apresentadas aos entrevistados sentenças, correspondentes a diferentes dimensões, como estrutura, responsabilidade, relacionamento (calor c apoio), recompensas (desenvolvimento pessoal) c manutenção e mudanças (riscos e conflitos). Litwin E STRINGer (1968) são autores importantes deste enfoque.

As abordagens tradicionais nos estudos de clima organizacional têm associado este conceito ao de motivação e, portanto, a fatores comportamentais, como liderança, relações interpessoais, satisfação no trabalho etc.

\subsubsection{Estudos de QVT}

À medida que os estudos e instrumentos de clima organizacional foram incorporando novas variáveis, foi sendo estruturado o conceito de qualidade de vida no trabalho - QVT. Com origem no referencial de TAvisTock, parte do pressuposto da existência de condições objetivas da estrutura sócio-técnica ou de padrões normativos para o trabalho condicionando o ambiente cultural. No entanto, a QVT é a "qualidade percebida", aquilo que cada empregado acha que ć, sendo portanto subjetiva (WESTLEY, 1979). 
Um dos modelos mais utilizados para avaliação de QVT é o de Hackman \& OldhaM ( 1975), bascado em caractcrísticas da tarefa, cujo instrumento é o Job Diagnostic Survey - JDS. O grupo de estudos coordenado por MORAES \& KILIMNIK (1989), em Belo Horizonte, traduziu c adaptou esse instrumento, usando-o em várias pesquisas.

Em recente dissertação de mestrado, Ramos (1995; p.25) sintetiza, a partir dos estudos de QVT realizados no Brasil nos últimos anos, as principais atividades pesquisadas, as abordagens teóricas mais freqüentes e as técnicas utilizadas. Concluiu que as pesquisas envolveram diferentes ramos e setores produtivos, de instituições de ensino a bancos, passando por construção civil, hospitais e empresas de informática. Walton, Hackman \& Oldhan, Wether \& Davis, Westley c Moos foram autores utilizados como referência. As técnicas de pesquisa empregadas incluem principalmente os questionários (survey), mas estes já são complementados em vários casos com entrevistas em profundidade e até brainstorming. Isto reduziria a principal fonte de limitações desses estudos, identificada como ressaltando apenas opiniões e percepções manifestas, não apreendendo características culturais menos visiveis.

\subsubsection{Comprometimento organizacional}

Mouday, Porter \& Steers (1982) chamam a atenção para as grandes confusões terminológicas que o termo Organizational commitment envolve. Propõem como seu conceito "a força relativa da identificação e envolvimento do indivíduo com uma determinada organização" (STEERs, 1977). Este autor salienta três fatores responsáveis pelo comprometimento organizacional: a) forte crença e accitação dos objetivos e valores organizacionais, b) desejo de dedicar energia em favor da organização, c) forte descjo de manter afiliação à organização.

Também aqui vêm sendo propostos instrumentos para auxiliar no estudo do tema. Van MaAnen \& Schein, em (1979), desenvolveram um modelo utilizando três dimensões relacionadas ao comprometimento dos indivíduos com as organizações: a dimensão funcional, referindose às tarefas desempenhadas pelos membros da organização; a dimensão hierárquica, dizendo respeito à distribuição dos cargos e chefias dentro da organização; inclusão, significando a inclusão do individuo na organização.

MorRow (1983) constatou a utilização, no estudo de comprometimento organizacional, de uma pluralidade ( cerca de 30 ) constructos e respectivas medidas, determinando a redundância de várias delas. Além disso, as pesquisas sobre atitudes sugerem modelos bidimensionais, 
sendo que, na verdade, algumas atitudes têm implicações sobre as outras. $E$, mais que isso, a análise não pode desconsiderar a complexidade das situações do cotidiano organizacional, onde ocorrem múltiplos compromissos simultâncos, alguns até contraditórios. É importante que, ao invés de um ou outro, sc leve $\mathrm{cm}$ conta um c outro. Pois os compromissos não são apenas com a organização, mas com a profissão, a carreira, o sindicato...

O estudo de Blau; Paul \& St. Jolin (1993) é importante como um dos pioneiros na consideração de múltiplos comprometimentos, a partir de instrumento baseado em quatro dos principais focos propostos por Morrow (Op.Cit): organização, carreira, valores e trabalho, excluindo o sindicato, já que a amostra analisada cra constituída por trabalhadores não-sindicalizados. Bastos \& Borges-ANDRADE (1995) centraram sua análise em três componentes do contexto de trabalho dos empregados de uma organização brasileira: a organização empregadora, o sindicato da categoria c a carreira/profissão.

\subsection{Abordagem psicológica}

\subsubsection{Enfoque cognitivo}

A partir do referencial da Psicologia Cognitiva, o enfoque cognitivo utiliza conceitos de aprendizagem individual - processamento de informações - para a compreensão dos mecanismos de representação da realidade social. Pretendendo superar certo pragmatismo da perspectiva behaviorista, preocupa-se com fenômenos mais complexos, como a aprendizagem de conceitos e solução de problemas, que não podem ser observados diretamente, c trabalha com representações e com o processamento de informações pelas pessoas. LOMÔNACO (1984) é uma referência importante desta perspectiva, que vem sendo utilizada nos estudos sobre aprendizagem organizacional e sobre como as organizações podem desenvolver capacidade para adquirir e transferir conhecimentos (SENGE, 1990; Garvin, I993; Fleury \& Fleury, 1995).

Para TuÉvenet (1986), cada organização possui uma cultura, resultante de múltiplos fatores, como a personalidade dos fundadores, atividade-fim da organização, política, filosofia e outros valores organizacionais. Deparam-se permanentemente com uma ambigüidade essencial, uma relacionada à contingência de sua interação com o ambiente e a outra à necessidade de manutenção c desenvolvimento da cocsão interna. "É o recurso e a conseqüência do modo pelo qual a empresa trata seus problemas de ambiente e coesão interna" (THÉVENET, 1991 p.33). Isto significa que a cultura é um instrumento para dar conta 
da multiplicidade de possibilidades de relacionamento individuo/ organização, valorizando mais a coerência do que a padronização. Para ele, do ponto de vista prático, a explicitação da cultura de uma organização ajuda a compreender $\mathrm{e}$ tratar seus problemas, sendo um suporte para aprender a aprender.

\subsubsection{Enfoque psicanalítico}

Utiliza a contribuição da Psicanálise para a análise dos fenômenos de identificação e de identidade individual e coletiva. $O$ conceito de identidade é concebido como um processo de construção social (BERGER, 1985; GoffMAN, 1989; Chanlat, 1992), relacionada ao desenvolvimento do self, ao significado e aos processos sociais (Deschamps, 1982). Essa construção tanto pode ser vivenciada como um processo puramente psicológico - coesão social a partir da identificação por sentimentos de afiliações afetivas - como cognitivo - identificação e sentido de pertencer a categorias como sexo, nacionalidade, afiliações políticas, religiosas etc. (Turner, 1982). Para Goffman (Op. Cit), os papéis sociais representados pelos indivíduos, ao expressarem regras sociais, constroem identidades e permitem que os indivíduos se integrem a grupos, constatando que pertencem a um coletivo (Chanlat, Op. Cit). ALBERT \& WheTtEM (1985) estabcleceram uma analogia entre identidade individual e identidade organizacional, compreendendo as crenças partilhadas pelos indivíduos sobre o que é central, distintivo e duradouro na organização. Wood JR. \& CALDAs (1995) ressaltam que "o conceito de identidade tem sido aplicado como metáfora no estudo de outros objetos, como grupos étnicos c nações" e propõem que a identidade organizacional seja entendida não como conceito, mas como metáforaraiz, um referencial para, complementando outros, ser usado na compreensão de fenômenos organizacionais.

HOFSTEDE (1980) desenvolveu um modelo empírico dentro dessa abordagem, a partir da análise de 116.000 respostas a um questionário utilizado com empregados de uma companhia multinacional que op$\mathrm{era} \mathrm{cm} 40$ paises. Usando análise fatorial, ele identificou quatro fatores ou dimensões que diferenciam grupos nacionais culturais. São eles: a - distância de poder (DP), significando o grau de aceitação por uma sociedade de desigualdade na distribuição de poder nas instituições $\mathfrak{e}$ organizações; b - tendência a evitar incerteza (EI), definida como o grau em que uma sociedade se sente ameaçada por situações ambiguas e incertas $\mathrm{e}$ reage pelo estabelecimento de regras firmes e exigência de conformismo; c - individualismo/coletivismo (IC), representando o posicionamento de uma sociedade num continuum definido pelas posições extremas individualista (crença de que as pessoas só devem 
cuidar de si e de sua família imediata) e coletivista (crença de que quando a socicdade ć organizada em grupos, essse têm a responsabilidade de cuidar de seus membros, que por sua vez lhes devem lealdade); $\mathrm{d}$ - masculinidade/feminilidade (MF), indicando a posição da socicdade num continuum definido pelas posições extremas machismo (aceitação de valores tradicionalmente associados ao sexo masculino, como agressividade, preocupação com a acumulação de dinheiro e bens materiais, ausência de preocupação com o bem-estar dos outros) e feminismo (accitação de valores tradicionalmente associados ao sexo feminino, em geral mais ligados a aspectos sentimentais). $\mathrm{O}$ autor ilustra algumas das dimensões arroladas para o ambiente organizacional, mostrando que a ênfase em resultados está associada ao machismo e uma baixa El implica maior disposição a correr riscos. Se um grupo ou individuo é mais individualista, seu envolvimento com a organização deverá ser influenciado por critérios calculistas (de interesse imediato), enquanto um mais coletivista prioriza o envolvimento de base moral. Quando a DP é baixa, há uma tendência de os chefes serem considerados pelos empregados como "pessoas como eu" e vice-versa.

Frente à crescente difusão das comunicações $\mathrm{e}$ do fenômeno da globalização, alguns autores defendem a idéia de que estaria se consolidando uma cra de identidade supranacional.

Com posição diferente, SAINSAUlieu ( 1985) dá uma contribuição importante, a partir do conceito de identidade de grupo como formas de sociabilidade fundadas na experiência comum e capazes de regular a ação coletiva, mas ressaltando a diversidade das identidades no interior das organizações. Adotando uma postura política, preocupa-se mais com as diferenças que com as similitudes, destacando que as empresas são compostas de subgrupos, com suas formas próprias de representação.

\subsection{Abordagem antropológica}

\subsubsection{Enfoque neo-evolucionista}

O conceito de cultura organizacional a partir da abordagem antropológica utiliza duas correntes: o neo-evolucionismo e o estruturalismo simbólico. Da primeira são excmplos WHite (1964) e STEWARD (1963), que afirmam que a cultura é integrada por três elementos: material tecnológico, sociológico e ideológico. Parte da análise dos processos de aculturação, formação de mitos, ritos e tabus para o conceito de cultura (substrato de crenças e valores) é usada para 
entender práticas formais e informais que constituem a dinâmica de cada organização. Não é uma caracteristica individual, mas significa que existe um conjunto de valores compartilhados pelos membros da organização.

\subsubsection{Enfoque simbólico}

A necessidade de encontrar os significados das relações entre os elementos da cultura de uma organização e que dão sentido ao quotidiano das mesmas justifica o apelo ao estruturalismo, dos quais SAHLINS (1988) c GEeRTZ (1987) são representantes. Este último concebe a cultura como uma "teia de significados", que o homem tece a seu redor e que o amarra. A cultura organizacional tem, assim, uma função de propor referentes que orientam seus integrantes no espaço organizacional.

De acordo com Beyer \& Trice, (1986), cultura é “o conjunto de concepções, normas e valores submersos à vida de uma organização e que devem ser comunicados a seus membros através de formas simbólicas tangiveis". O estudo desses autores ressalta a importância da forma tangivel que esses valores devem assumir para serem afirmados e comunicados aos membros da organização. Isto inclui os ritos, categoria privilegiada para o estudo da cultura das organizações, na medida $\mathrm{cm}$ que envolvem mitos, histórias, gestos e artefatos visíveis. Estes autores destacam ainda que os ritos são facilmente identificados, mas dificeis de serem interpretados, podendo ser classificados nas organizações contemporâncas $\mathrm{cm}$ seis tipos: ritos de passagem, de degradação, de confirmação, de reprodução, de redução de conflito e de integração.

Este enfoque utiliza o método etnográfico, tradicionalmente usado pela Antropologia Social, para pesquisar os fenômenos ligados à cultura organizacional, com seus valores, ethos, imaginário, visão de mundo $\mathrm{e}$ sistemas simbólicos. As representações sociais, entendidas como conhecimentos práticos socialmente construidos com a finalidade de dar sentido à realidade cotidiana (SATO, 1995), são fundamentais à abordagem. Busca-se apreender os seus significados (sua densidade simbólica). A descrição etnográfica baseia-se na palavra dos informantes e a interpretação do pesquisador compartilha o significado com os informantes, que possuem, na verdade, o roteiro simbólico do que concebem e articulam logicamente entre suas visões de mundo. $O$ respeito rigoroso da visão que os nativos têm sobre os aspectos analisados (sobre si mesmos, seus conhecimentos e práticas cotidianas e sua concepção do mundo) é fundamental (GeerTz, 1978). Uma atitude de estranhamento obriga o pesquisador a introduzir a dúvida sistemática como regra do método, suspendendo valores prevalecentes e de senso comum para melhor captar o sentido. Aquilo que é familiar se transforma $\mathrm{cm}$ exótico. 
Para RuBen et al. (1955), a utilização da antropologia na análise de organizações teve o intuito de dar conta de uma série de resíduos que os paradigmas convencionais não conseguiam analisar, dos quais sobressaem a linguagem, o simbolismo, o espaço, tempo e cognição. Esta abordagem se intensificou na década de 80 , gerando críticas principalmente por parte dos antropólogos de formação (AкTouf, 1992). Para eles, o grande mérito desses estudos foi justamente chamar a atenção para a dimensão simbólica que permeia a organização e seus grupos. Entretanto, negam a existência de uma "cultura", no sentido antropológico, definida nos limites da organização e, principalmente, negam a possibilidade de gestão dessa cultura, na medida em que a organização está inserida numa socicdade e, portanto, permeada pela cultura dessa sociedade.

Outras limitações que têm sido apontadas no uso das abordagens antropológicas para os estudos de cultura organizacional dizem respeito à dificuldade de operacionalização do próprio conceito de cultura, muitas vezes visto como tábua de salvação ou vala comum para todos os problemas de difícil interpretação. Além disso, implicam maior complexidade para a obtenção dos dados, com mais tempo destinado às entrevistas para a escuta do outro e para o diálogo das diferenças.

\section{3. Abordagens interdisciplinares}

O objetivo das abordagens interdisciplinares é reduzir as limitações dos enfoques unidimensionais na análise de fenômeno tão complexo quanto a cultura de uma organização. Evita-se a postura estritamente empirista, que considera a sociedade como um somatório de indivíduos, buscando também o que parece irracional nas organizações. Os arranjos de enfoques são variados, dependendo do objetivo de aprofundamento de um ou outro aspecto, mas tendo sempre em comum a preocupação de ampliar a capacidade de análise e compreensão do fenômeno. Assim, encontram-se estudos que mesclam perspectivas psicológicas com antropológicas; outros que combinam escalas quantitativas $\mathrm{c}$ indicadores mais objetivos com análises em profundidade de valores e representações simbólicas. Outros, ainda, ressaltam como fundamentais a apreensão das relações de poder entre os membros da organização, quer individualmente ou em grupos, e também as relações de poder externas às organizações e que têm reflexos internamente.

As técnicas de investigação propostas para as abordagens interdisciplinares são preferencialmente qualitativas, mas o método triangular tem sido defendido como facilitador da abrangência da análise pretendida. Este inclui observação direta, análise de documentos, 
técnicas qualitativas (especialmente para captar os elementos simbólicos) e técnicas quantitativas (importantes para referendar achados subjetivos).

Um dos autores freqüentemente referenciados nos estudos interdisciplinarcs de Cultura Organizacional é ScherN $(1981 ; 1986)$. Para ele, cultura é o "conjunto de pressupostos básicos que um grupo inventou, descobriu ou desenvolveu ao aprender como lidar com os problemas de adaptação externa e integração interna e que funcionaram bem o suficiente para que scjam considerados válidos $\mathrm{c}$ ensinados a novos membros como a forma correta de perceber, pensar e sentir, em relação a esses problemas". Propõe três níveis para o entendimento da cultura de um grupo: 1 - pressupostos básicos; 2 - valores e ideologia; 3 - artefatos visiveis (manifestações materiais). Entre os pressupostos básicos, o autor ressalta a orientação relativa ao tempo e seu uso; a relação do homem com a natureza; os conceitos dc espaço e o relacionamento dos homens entre si. Entre os valores e ideologia, inclui os ideais $\mathrm{e}$ as normas de comportamento. E, no último nível, a linguagem, a tecnologia e a organização social. Reconhece que a grande responsabilidade pela criação e transformação da cultura, através principalmente da definição dos pressupostos básicos, cabe aos membros da organização, mas atribui um papel singular aos fundadores e/ou heróis das organizações, que marcam com sua visão de mundo os valores que serão compartilhados. São, portanto, diferenciados os papéis de produção c de socialização de padrões culturais no interior das organizações.

Belle (1991), conforme sua própria declaração, utiliza uma mescla das abordagens psicanalítica, antropológica e cognitiva para a compreensão das relações entre identidade e cultura.Conceitua cultura como "um conjunto de significações lentamente claboradas, transmitidas $\mathrm{e}$ ativas nas relações $\mathrm{dc}$ trabalho, fornecendo às pessoas possibilidade de interpretação de suas situações. É a partir da especificidade cultural de cada empresa que as pessoas construirão sua identidade profissional" (Op.Cit.P.43). Diferentemente dos adeptos da linha da corporate culture, acredita quc as regulações culturais são coletivamente aceitas mais pela dominação de atores fortes que pela difusão de uma cultura dominantc. Cita Lévy Strauss (1977) para ressaltar que a cultura social é muito mais o resultado de articulações de diferenças que o compartilhamento sem conflitos de valores e representações comuns. E sugere, com Sainsaulieu (1985), que se estude, além dos valores comuns da organização, as identidades fortes encontradas nos grupos profissionais (de oficio), de idade, sexo, cargos e funções etc. Os valores comuns refletem tanto o nível político - responsável pelo projeto e fundamentos da organização, formulados 
pelos fundadores, pela história e estratćgias da organização - quanto o estrutural, no qual têm expressão concreta, através da estrutura hierárquica e do sistema de gestão. Mas a grande contribuição desta perspectiva é justamente mostrar que estes dois niveis têm valor cultural, operando também no universo simbólico, no qual o imaginário organizacional cria a possibilidade de cada um encontrar o seu lugar. A cultura funcionaria, assim, como o recurso para se entender a articulação do funcional-real com o imaginário. Propõe três grupos de opostos para operacionalizar o estudo das imagens construidas pelas organizações: poder/vulnerabilidade; consenso/divisão e mudança/ordem.

FLeURY \& Fischer (1989), em suas próprias palavras, tentam recuperar raizes da Antropologia, especialmente os estudos de BEYER \& TRICE (1986), e do interacionismo simbólico, principalmente BERGER \& LuckMan (1967), para o estudo da cultura nas organizações. Embora a questão do poder não seja central em nenhuma das duas fontes, a dimensão simbólica é fundamental, destacando-se a preocupação, na pesquisa etnográfica, em desvendar os significados das práticas sociais e, na Sociologia do Conhecimento, os processos de legitimação e socialização. Para suprir a ausência, nestes estudos, da dimensão de poder, sugerem a incorporação da dimensão politica, utilizando a contribuição de PAGEs el al. . (1987). Assim, para as autoras, cultura organizacional é "um conjunto de valores e pressupostos básicos, expresso em elementos simbólicos que, em sua capacidade de ordenar, atribuir significações e de construir a identidade organizacional, tanto agem como elementos de comunicação e consenso, como ocultam e instrumentalizam as relações de dominação". Como proposta metodológica, propõem o estudo do histórico das organizações, dos processos de socialização de novos membros, das politicas de recursos humanos, dos processos de comunicação e as formas de organização do processo de trabalho. 
QUADRO $1^{*}$

Classificação das abordagens de

Cultura nos estudos organizacionais

\begin{tabular}{|c|c|c|c|c|c|}
\hline A bordagens & Enfoque & $\begin{array}{l}\text { Autores } \\
\text { Selecionados }\end{array}$ & $\begin{array}{l}\text { Palavras- } \\
\text { Chave }\end{array}$ & $\begin{array}{l}\text { Aspectos } \\
\text { Metodologjico }\end{array}$ & Critica \\
\hline & & $\begin{array}{l}\text { Handy- } \\
\text { Salazar }\end{array}$ & $\begin{array}{l}\text { Corporate/ } \\
\text { culture }\end{array}$ & $\begin{array}{l}\text { Comportamen- } \\
\text { tos observáveis } \\
\text { e mensuráveis }\end{array}$ & Empiricismo \\
\hline \multirow[t]{3}{*}{$\begin{array}{l}\text { COMPOR- } \\
\text { TAMENTAL }\end{array}$} & Clima & Moos & $\begin{array}{l}\text { Satisfaça/ } \\
\text { insa tis fação } \\
\text { percabida }\end{array}$ & $\begin{array}{l}\text { Escalas de } \\
\text { Ambiente de } \\
\text { Trabalho }\end{array}$ & Subjetivismo \\
\hline & QVT & $\begin{array}{l}\text { Westley; } \\
\text { Hackman } \\
\text { Oldham; } \\
\text { Wether/Davis }\end{array}$ & $\begin{array}{l}\text { Estrutura } \\
\text { sócio- } \\
\text { tccnológica, } \\
\text { ambionte } T\end{array}$ & $\begin{array}{l}\text { Características } \\
\text { da Tarefa } \\
\text { (JDS) }\end{array}$ & $\begin{array}{l}\text { Percepção } \\
\text { manifesta }\end{array}$ \\
\hline & $\begin{array}{l}\text { Comprometi- } \\
\text { mento }\end{array}$ & $\begin{array}{l}\text { Mouday et al. } \\
\text { Stcers Morrow; } \\
\text { Van Maanen }\end{array}$ & $\begin{array}{l}\text { Afiliação } \\
\text { Identificaçåo } \\
\text { Envolvi- } \\
\text { mento }\end{array}$ & $\begin{array}{l}\text { Constructos } \\
\text { atitudinais }\end{array}$ & $\begin{array}{l}\text { Atitudes } \\
\text { bidimensionais }\end{array}$ \\
\hline
\end{tabular}

\begin{tabular}{|c|c|c|c|c|c|}
\hline $\begin{array}{l}\text { PSICO- } \\
\text { LÓGICA }\end{array}$ & Cognitivo & $\begin{array}{l}\text { Lomônaco; } \\
\text { Fleury \& Fleury; } \\
\text { Thévenet }\end{array}$ & $\begin{array}{l}\text { Aprendizado, } \\
\text { coesäo } \\
\text { externa/ } \\
\text { intema }\end{array}$ & $\begin{array}{l}\text { História, } \\
\text { simbolos, } \\
\text { lógica }\end{array}$ & Complexidade \\
\hline & $\begin{array}{l}\text { Psicana- } \\
\text { lítico }\end{array}$ & $\begin{array}{l}\text { Berger, } \\
\text { Goffman; } \\
\text { Chanlat; } \\
\text { Tumer }\end{array}$ & $\begin{array}{l}\text { Identidade } \\
\text { afetiva e } \\
\text { cognitiva }\end{array}$ & $\begin{array}{l}\text { Obstrvação } \\
\text { direta; } \\
\text { entrevistas }\end{array}$ & Mctá fora \\
\hline \multirow[t]{2}{*}{$\begin{array}{l}\text { ANTROPO } \\
\text { LÓGICA }\end{array}$} & $\begin{array}{l}\text { Noo- } \\
\text { cvolucionista }\end{array}$ & White ; Steward & $\begin{array}{l}\text { Compar- } \\
\text { tilhamento }\end{array}$ & $\begin{array}{l}\text { Método } \\
\text { etnográfico }\end{array}$ & In terpre tação \\
\hline & $\begin{array}{l}\text { Istrutural- } \\
\text { simbólico }\end{array}$ & $\begin{array}{l}\text { Geert:; } \\
\text { Beyer/Trice }\end{array}$ & $\begin{array}{l}\text { Crenças - } \\
\text { Valores }\end{array}$ & $\begin{array}{l}\text { Significados/ } \\
\text { representações }\end{array}$ & Residuo \\
\hline \multirow[t]{2}{*}{$\begin{array}{l}\text { INTERDIS- } \\
\text { CIPLINAR }\end{array}$} & $\begin{array}{l}\text { Psico- } \\
\text { an tropológico }\end{array}$ & Schein; Belle & $\begin{array}{l}\text { Pressupostos } \\
\text { B }\end{array}$ & $\begin{array}{l}\text { Ritos, valores/ } \\
\text { artefatos }\end{array}$ & Complexidade \\
\hline & $\begin{array}{l}\text { Antropo- } \\
\text { politico }\end{array}$ & Meury \& Fischer & $\begin{array}{l}\text { Consenso/ } \\
\text { Oculto }\end{array}$ & & $\begin{array}{l}\text { História, } \\
\text { simbólico }\end{array}$ \\
\hline
\end{tabular}

124 Rusumo das abordagens apresentadas e suas principais caracteristicas. 


\section{Cultura das Organizações Públicas}

Conforme sistematizado no item anterior, são múltiplas as possibilidades teóricas e metodológicas para o estudo de cultura em organizações. No entanto, julga-se procedente ressaltar alguns aspectos que podem reduzir os riscos de viés e simplismos nas análises do tema.

Parece consensual que as perspectivas interdisciplinares são preferiveis às abordagens unidimensionais para a análise da cultura $\mathrm{cm}$ organizações de modo geral e das organizações públicas de maneira particular. Também os procedimentos metodológicos complementares, especialmente os triangulares, permitem uma abrangência maior, devendo-se levantar informações de diferentes atores envolvidos. Scm se deter na polêmica sobre singularidade das organizações públicas, a complexidade dessas organizações, com suas dicotomias e ambigüidades clássicas - eficiência e objetivos sociais; controle e agilização; universalismo e representatividade; critérios técnicos e demandas sociais... - aumenta a dificuldade de serem estudadas utilizando-se uma única fonte teórica e metodológica.

Por outro lado, o fato de serem financiadas pelos contribuintes faz com que o interesse a respeito de seu funcionamento e resultados seja muito amplo, quase sempre já contaminado por imagens e valores sociais prevalentes. Assim, o nível simbólico deverá ser privilegiado nos estudos da cultura de organizações públicas.

Embora sejam freqüentes as representações negativas do funcionário público — "barnabé" "maria-candelária"; "aspone" (VenEU, 1990), pesquisas com esse grupo têm revelado valores compartilhados de orgulho $\mathrm{c}$ idealismo (espírito público), sugerindo estudos mais sistemáticos que esclareçam os mitos e lugares comuns (Frasça, 1993). As imagens e valores predominantes na sociedade sobre as organizações públicas e sobre o funcionário público parecem ser marcados por uma "perene convivência de contrários", ou, nas palavras de Roberto DAMATTA, pela "duplicidade atravessadora do sistema simbólico da cultura brasilcira" (DAMATTA, 1983). Esta ambigüidade tem raizes na própria história brasileira, identificada em múltiplas situações: casa-grande/senzala, autoritarismo/descentralização, autonomia/ controle, tccno-burocratismo/clicntelismo, orgulho/desmotivação, corrupção/solidariedade, formalização/formalismo, desenvolvimento/ subdesenvolvimento. A dicotomização refletiria ainda, scgundo DaMatTa (1985), as duas éticas componentes da cultura brasileira: a ética burocrática e a ética pessoal, condicionando as representações sociais da administração pública brasileira. 


\section{Bibliografia}

Aktouf, Omar. "O simbólico e a cultura de empresa". In Chanlat, J.F.(org.). O individuo na Organização - dimensðes esquecidas. São Paulo, Atlas, 1992.

Albert, S. \& Wehetten, D. "Organizational identity". In: Cummings, L.L;Staw, B.M. (eds). Research in organizational hehavior. v. 7, p.263-95. Greenwich, Jai Press, 1985.

Bastos, Antonio V. \& Borges-Andrade, Jairo E. "Comprometimento no Trabalho: identificando padrões de compromentimento do trabalhador com a organização, a carteira e o sindicato". Revista Brasileira de Administração Contemporänea. v.1, n.6, p. 220-240, Rio de Janeiro, ANPAD, 1995

Belle, Françoise. "Cultura de empresa e identidades profissionais". Revista de Administração, São Paulo, v.16, n.2, p.40-59, abr/jun, 1991.

Berger \& Luckmann. A construção social da realidade. Petrópolis, Vozes, 1985.

BeYer, J. \& Trice, H. "How an organizations's rite reveal its culture". In : Onganizational Dymamics, 1986.

Chanlat, Jean François(Coord). O individuo na Organização: dimensôes esquecidas. São Paulo, Atlas, 1992.

DAMATTA, Roberto. Camavais, malandros e heróis: para uma sociologia do dilema brasileiro. Rio de Janciro, Zahar, 1983. A casa e a nua: espaço, cidadania, mulher e morte no Brasil. São Paulo, Brasiliense, 1985.

Deschamps, Claude J. "Social identity and relations of power between groups". In: TAJfEL, H.(ed). Social identity and intergroup relations. Cambridge University Press, 1982.

Fleury, M.Tereza L. \& Fischer, Rosa M. Cultura e Poder nas Organizaçz̃es. São Paulo, Atlas, 1989.

FleURY, Afonso \& FleURY, Maria Tcreza L. Aprendizagem e Inovação Organizacional. São Paulo, Atlas, 1995.

França, Bárbara Heliodora. O bamabé: consciência politica do pequeno funcionário público. São Paulo, Cortez, 1993.

Freitas, M.E. Cultura organizacional: formaçao, tipologia e impactos. São Paulo, Makron Books, 1991.

Garvin, D. Building a learning organization. Harvard Business Review, july/aug, 1993.

Geertz, Clifford. A imterpretação das Culturas. Rio de Janeiro, Zahar, 1987.

Goffman, Erving. A representaçao do Eu na vida cotidiana. Petrópolis, Vozes, 1989.

Hackman, J. \& Oldham, G. "Development of the job diagnostic survey". Journal of Applied Psychology. v.60, n.2, p.159-170, 1975.

Handy, C.B. Como compreender as Organizaçðes. Rio de Janeiro, Zahar, 1978.

Hofstede, G. Culture's Consequences. Beverly Hills, CA, Sage Publications, 1980.

Neuin, B; Chuatd, D; Sanders, G. "Measuring organizational cultures: a qualitative and quantitative study across twenty cases". Administrative Science Quartely. n. 35, p.286-316, june, 1990.

JAEGER, Alfred M. "Desenvolvimento organizacional e culturas nacionais". Anais da $L X$ ANPAD. p.305-309, 1985. 
Lawrence, P.R. \& Lorsch, J.W. As empresas e o ambiente. Petrópolis, Vozes, 1973. Levy-Strauss, Claude. L'identité. Paris, Grasset, 1977.

Lomónaco, F. Psicologia da aprendizagem. São Paulo, Edgar Blucher, 1970.

I.ITwiN, George H. "Climate and motivation: an experimental study". In: KolB et al. Organizational Psychology. A book of readings. Englewood Cliffs, PrenticeHall, 1971.

MARTIN, J. Cultures in organization : three perspectives. New York, Oxford UniversityPress, 1992

Mornes, Lúcio F. \& Kilımnik, Zélia. A qualidade de vida no trabalho burocrático automatizado. Belo Horizonte, UFMG, 1989 (Relatório de Pesquisa).

Morrow, P.C. "Concept redundancy in organizational research: the case of work commitment. Academy' of Management Review, v. 8, n.3, p.486-500, 1983.

Mouday, R.T; Porter, L.W. \& Steers, R.M. Employee-Organization linkages- the Psychology of conmitment,absenteism, and tumover. New York, Academic Press, 1982.

PAGĖs, M. et al. O poder das organizações. São Paulo, Atlas, 1987.

Ramos, Wilsa Maria. " $\wedge$ qualidade de vida no trabalho de médicos e enfermeiros: um estudo de casos em hospital público de Belo Horizonten ${ }^{n}$. Belo Horizonte, UFMG, 1995 (dis. mestrado).

Rodrigues, Suzana B. "Corporate culture and identity: de-institutionalization in a brazilian telecomunications company". In: Egos Congress, II, Paris, Julho, 1993.

Ruben, Guilhermo; Serva, Mauricio; Castro, Marco I. "Resíduos e complementariedade: das relações entre a Teoria da Administração e a Antropologia". Revista Brasileira de Administração Contemporinea. Vol.1, n.6, p.206-217, 1995.

Sainsaulieu, R. L'identité au travail. Paris, Presse de la Fondation Nationale des Sciences Politiques, 1977.

"Culture et sociologie de l"entreprise". Connexions, n.45, p.109$122,1985$.

SAlAZAR, German Torres. "Cultura gerencial e estratégias empresariais: um estudo em empresas agropecuárias". Revista de Administrą̧ão de Empresas, v. 32, n.5, p.28-37, nov/dez, 1992.

Saht.sss, Marshall. Cultura e Razão Prática. Rio de Janeiro, Zahar, 1979.

SAто. Leny. "O conhecimento do trabalhador e a teoria das representaçð̃es sociais". In: O sofrimento psiquico nas organizaçzes. Petrópolis, Vozes, 1995.

Schein, E. Organizational culture and leadership. San Francisco, Jossey Bass, 1986.

SMIRcich, L. "Concept of culture and organizational analysis". Administrative Science Quartely, n.28, p.339-350, 1983.

SENGE, P. The fifth discipline. New York, Doubleday, 1990.

Steers, R.M. "Antecedents and outcomes of organizational commitment". Administrative Science Quartely, v.22, p.45-56, 1977.

Stringer, Robert A,Jr. "Achievement motivations and management control". In: Dalton, Gene \& Lawrence, Paul R.(eds). Motivation and comtrol in organizations. Homewood, Dorsey Press, 1971.

Tuévenet, Maurice. Audit de la culture d 'entreprise. Paris, Les Editions d'Organisation, 1986.

-- "A cultura de empresa hoje em dia". Revista de Administração. São Paulo, USP, v.26, n.2, p.32-39, abril/junho, 1991.

TURNER, John C. "Towards a cognitive redefinition on the social group". In; TAJFEL(ed), Social identity and intergroup relations. Cambridge University Press, 1982. 
VAn MAanen, J, \& Schein, H. "Toward a theory of organizations socialization". In: Staw, B.M.(ed.). Research in organizational behavior. Jay Press, 1979, v.1, p.209-264.

Veneu, Marcos Guedes. "Representações do funcionário público". Revista de Administração Pública. Rio de Janeiro, EBAP/FGV, v.24, n. 1, p.5-16, nov 1989/ jan 1990.

WALTON, R. "Quality of working life: What is it?" Sloan Management Review, v.15, n.1, p.11-21, 1973.

Wether, W.B; Davis, K. Administração de pessoal e recursos humanos. São Paulo, MacGraw -Hill, 1983.

Westley, William. Qualidade de vida no trabalho: problemas e soluçðes. Rio de Janeiro, Incisa, 1979.

Wood Jr. Thomaz \& CalDas, Miguel P. "Quem tem medo de eletrochoque? Identidade, Terapias Convulsivas e Mudança Organizacional". Revista de Administração de Empresas, São Paulo, v.35, n.5, p.13-21, set/out, 1995.

\section{Resumo \\ Resumen \\ Abstract}

\section{Cultura e Organizações Públicas \\ Moema Miranda de Siqueira}

O artigo apresenta uma classificacão das abordagens de Cultura nos estudos organizacionais. A abordagem comportamental compreende os enfoques sistêmico e de clima organizacional, os estudos informados pelo conceito de Qualidade de Vida no Trabalho - QVT, e a perspectiva do comprometimento organizacional; a abordagem psicológica abrange os enfoques cognitivo e psicanalítico; a abordagem antropológica, os enfoques neo-evolucionista e simbólico e a abordagem interdisciplinar, os enfoques psico-antropológico e antropo-politico. $\dot{A}$ guisa de conclusão, a autora tece algumas consideraçðes sobre as abordagens mais adequadas ao estudo das organizaçðes públicas.

\section{Cultura y Organizaciones Públicas \\ Moema Miranda de Siqueira}

El articulo presenta una clasificación de los abordajes de Cultura en los estudios referentes a la organización. El abordaje del comportamiento comprende los enfoques sistémico y de clima organizacional, los estudios informados por el concepto de Calidad de Vida en el Trabajo - CVT, y la perspectiva del comprometimiento organizacional; el abordaje psicológico abarca los enfoques cognitivo y psicanalitico; el abordaje antropológico, los enfoques neoevolucionista y simbólico y el abordaje interdisciplinar, los enfoques psicoantropológico y antro-politico. A guisa de conclusión, la autora hace algunas consideraciones acerca de los abordajes más adecuados al estudio de las organizaciones públicas. 
The article presents a classification of approaches to culture in organisational studies. The behavioural approach encompasses the systemic and organisational focuses, the studies based upon the Quality of Life at Work concept - QLW, and the prospect of organisational compromise; the psychological approach encompasses the cognitive and psycho-analytical focuses; the anthropological approach deals with the neo-evolutionist and symbolical focuses; and the interdisciplinary approach analyses the psycho-anthropological and anthropo-political focuses. As a conclusion, the author develops views on the most appropriate approaches for the study of public organizations. 